ISSN 2447-9071

doi $10.36414 /$ rbmc.v5i12.6
Contato para correspondência: Antonio Márcio Teodoro Cordeiro Silva

E-mail:

marciocmed@gmail.com

Conflito de interesse: Não

Financiamento: Recursos próprios

Recebido: 19/06/2019

Aprovado: 13/08/2019

\title{
Avaliação do serviço de residência terapêutica sob a percepção de seus usuários e dos profissionais de saúde
}

\section{Evaluation of therapeutic residence service in the perception of users and the health professionals}

Pedro Uriel Gonçalves Lima', Jacqueline Andréia Bernardes Leão Cordeiro² ${ }^{2}$ Cesar Augusto Sam Tiago Vilanova-Costa ${ }^{3}$, Antonio Márcio Teodoro Cordeiro Silva ${ }^{4}$

\begin{abstract}
'Médico, Mestre em Ciências Ambientais e Saúde pela PUC Goiás, 'Enfermeira, Doutora em Enfermagem, Professora da Faculdade de Enfermagem da Universidade Federal de Goiás, ${ }^{3}$ Biólogo, Doutor em Ciências Biológicas, Laboratório de Biologia Tumoral e Oncogenética do Hospital Araújo Jorge, ${ }^{4}$ Biomédico, Doutor em Biologia Celular e Molecular, Professor do Curso de Medicina e do Programa de Pós-Graduação em Ciências Ambientais e Saúde da PUC Goiás, Professor da Faculdade da Polícia Militar.
\end{abstract}

\section{Resumo}

A implantação dos Centros de Atenção Psicossocial e Residências Terapêuticas se impuseram como respaldo para o novo modelo de atendimento a estes pacientes. Por meio de Escalas Brasileiras de Avaliação da Satisfação objetivou-se neste estudo avaliar o grau de satisfação de moradores e funcionários dessas residências, para refletirse tais moradias trouxeram ou não benefícios propostos pela Lei. Foi constatado que apenas 1,9\% dos profissionais se disseram muito insatisfeitos com o serviço, a maioria, $62,7 \%$, estão satisfeitos com o trabal ho que realizam. Com relação aos residentes, alguns dados chamam a atenção, tais como $44,4 \%$ se sentem respeitados pelos profissionais, $66,7 \%$ sentem que os profissionais compreendem muito bem seus problemas. Após analisar o material verbal coletado nas entrevistas dos profissionais e dos moradores, foi possivel compreender as insatisfações dos profissionais quanto a questões salariais e incentivos à qualificação, além de perceber o quanto o morador éacolhido pelo serviço.

Palavras-Chave: Moradias Assistidas, Instituições Residenciais, Transtornos Mentais, Profissional de Saúde.

\begin{abstract}
The implementation of Psychosocial and Therapeutic Residences Care Centers have been imposed as support for the new model of care for these patients. Through Satisfaction Assessment Scales Brazilian was aimed in this study to evaluate the degree of satisfaction of residents and staff of these homes, to reflect whethersuch dwellings or not brought benefits proposed by the Law. It was found that only $1.9 \%$ of the professionals of the Therapeutic Residences said they were very dissatisfied with the service, the majority, $62.7 \%$, are satisfied with the work they do. With regard to residents, some data draw attention, such as $44.4 \%$ feel respected by professionals, 66.7\% feel that professionals understand well your problems. After analyzing the verbal material collected in interviews of professionals and residents, it was possible to understand the dissatisfaction of professionals as to salary issues and incentives for training and realize how much the occupant is received by the service.
\end{abstract}

Keywords: Assisted Living Facilities, Residential Institutions, Mental IIIness, Mental Health Professional. 


\section{Introdução}

A assistência ao paciente portador de transtorno mental no Brasil, ao longo dos anos, se aprimorou e buscou atender as propostas provenientes da Reforma Psiquiátrica, que exige dos profissionais de saúde uma prática contrária àquela iniciada com a psiquiatria tradicional, caracterizada pelo isolamento, tratamento punitivo e contenção física e química dos pacientes ${ }^{1}$. A transformação da prática assistencial psiquiátrica vem ocorrendo de forma lenta e gradual, mesmo quando implicações éticas e legais evidenciam a necessidade de aceleração desse processo².

A reforma psiquiátrica brasileira, iniciada na década de 1980, implementou novas propostas e possibilidades de assistência ao paciente com transtorno mental, procurando assim assegurar o exercício de seu direito à cidadania3. Ao se redirecionar a Política de Saúde Mental no país, passouse a um processo de transformação da conduta terapêutica para o portador de transtorno mental, que era contrária à sua reclusão em hospitais psiquiátricos, sendo criados os Centros de Atenção Psicossocial (CAPS), como serviços substitutivos extra hospitalares com a finalidade de reduzir internações psiquiátricas e a ressocialização do paciente ${ }^{2,3}$.

Os CAPS devem funcionar como prestação de serviços terapêuticos, individuais ou em grupos, tais como: oficinas, atividades lúdicas, visitas domiciliares, atendimento às famílias e atividades comunitárias ${ }^{4}$. Além disso, os CAPS promovem a articulação entre os diversos dispositivos extra-hospitalares da rede de atenção à saúde mental do município ${ }^{5}$.

Para completar o ciclo de reestruturação de apoio à Reforma Psiquiátrica, foram criadas as residências terapêuticas, ambiente no qual os portadores de transtorno mental exercem sua inserção em um ambiente próximo ao que se pode considerar como uma residência, tal como conhecemos e onde devem, progressivamente, se tornar capacitados para o exercício de direitos e deveres da vida comum ${ }^{6}$.

O Serviço Residencial Terapêutico (SRT), ou residência terapêutica ou simplesmente "moradia", são casas localizadas no espaço urbano, constituídas para responder às necessidades de moradia de pessoas portadoras de transtornos mentais graves, institucionalizadas ou não. O número de usuários pode variar desde um único indivíduo até um pequeno grupo de no máximo oito pessoas, que deverão contar sempre com suporte profissional sensível às demandas e necessidades de cada um ${ }^{7}$.

As residências terapêuticas têm como principal finalidade o morar, não devendo ser consideradas como locais onde são realizados serviços de saúde, uma vez que são articuladas aos demais dispositivos que integram a rede de atenção à saúde mental. Podem beneficiar portadores de transtornos mentais egressos ou não de hospital psiquiátrico, que não possuam suporte familiar, egressos de hospitais de custódia, por meio de decisão judicial, pessoas acompanhadas pelo CAPS, que possuem problemas de moradia identificados pela equipe interdisciplinar e moradores de rua acometidos de transtornos mentais com acompanhamento dos CAPS $^{7,8}$.

O acompanhamento a um morador deve prosseguir, mesmo que ele mude de endereço ou eventualmente seja hospitalizado. $O$ processo de reabilitação psicossocial deve buscar, de modo especial, a inserção do usuário na rede de serviços, organizações e relações sociais da comunidade. $\mathrm{Ou}$ seja, a inserção em um serviço de residência terapêutica é o início de longo processo de reabilitação que deverá buscar a progressiva inclusão social do morador?

De acordo com os últimos levantamentos, o Brasil possui 32 mil leitos psiquiátricos, resultado da redução de aproximadamente 84 mil leitos nos últimos 11 anos. Existem 779 residências terapêuticas em funcionamento, nos quais moram 3.091 pessoas de ambos os sexos ${ }^{7}$.

Estimativas recentes do Ministério da Saúde apontam a existência de aproximadamente 12.000 pacientes internados que poderiam ser beneficiados pelas residências terapêuticas. Tais dados evidenciam a necessidade de significativa expansão do número de residências, de modo a reduzir a segregação e aumentar a reinserção social dos pacientes ${ }^{9}$.

Para a implantação de uma residência terapêutica é necessário o comprometimento entre gestor, comunidade, usuários, profissionais de saúde, vizinhança, rede social de apoio, além de cuidadoso e delicado trabalho clínico com os futuros moradores.

As residências terapêuticas como propostas de ressocialização de doentes mentais que estiveram internados por longos períodos em manicômios inóspitos com tratamentos desumanos poderá ser uma solução9. Para tanto, é necessário preservar os ditames estabelecidos em lei, bem como conhecer os reais níveis de satisfação por parte daqueles que ali convivem diariamente, ou seja, profissionais e usuários das residências terapêuticas. Assim, o objetivo deste artigo é avaliar o serviço de residência terapêutica sob a ótica de seus profissionais e pacientes.

\section{Métodos}

Trata-se de um estudo transversal analítico com abordagem quantitativa e qualitativa. A pesquisa foi realizada no município de Palmelo/GO. É uma cidade que nasceu em torno da cultura religiosa espírita, tendo se desenvolvido inicialmente pela imigração de pessoas em busca de "cura" de doenças, principalmente as mentais. Muitos doentes foram deixados 
pelos seus familiares à mercê da caridade e acolhimento dos religiosos. A partir de então, foi criado um sanatório espírita, em que doentes com ou sem referência familiar eram internados para tratamento espiritual.

Esta pesquisa foi efetivada em três residências terapêuticas e um CAPS do referido município. Tais locais tiveram sua origem a partir da necessidade de se acomodar e dar assistência aos pacientes que estavam internados no sanatório espírita, fechado após a reforma psiquiátrica.

Para a realização desta pesquisa foram aplicados os questionários de Escala Brasileira de Avaliação da Satisfação (SATIS-BR) aos usuários e aos profissionais das residências terapêuticas. A amostra contou com nove moradores adultos de ambos os sexos, desde que tivessem boa capacidade de compreensão e entendimento para responder aos questionamentos e 18 funcionários: dez do CAPS e oito das residências terapêuticas, de ambos os sexos, prestadores de serviços de vários tipos de vínculos empregatícios e de vários graus de formação.

A satisfação dos usuários e profissionais foi avaliada pela SATIS-BR. É uma escala elaborada pela Divisão de Saúde Mental da Organização Mundial da Saúde (OMS), que já foi validada no Brasil10. Ela utiliza-se de uma escala tipo Likert de cinco pontos, na qual, o número cinco representa maior satisfação e o número um, menor satisfação.

Os dados quantitativos obtidos nos questionários referentes às perguntas objetivas, foram organizados em planilhas no software Microsoft Office Excel 2013, segundo gênero, estado civil e idade. Adicionalmente, foram aplicados cálculos de estatística descritiva.

Os dados qualitativos foram analisados com base no método do discurso do sujeito coletivo, que visa a tabulação e organização dos dados e tem como fundamento a teoria da representação social ${ }^{11}$. Esse método de análise é um discurso-síntese, criado com a junção de discursos de sentido semelhante, por meio de procedimentos sistemáticos e padronizados ${ }^{12}$.

A técnica consiste basicamente em analisar o material verbal coletado nas entrevistas, destacados pelo pesquisador e que revelam a essência do conteúdo do discurso, de forma a extrair ideias centrais agrupadas em discursos-síntese semelhantes ${ }^{13}$.

Antes da aplicação do questionário, o trabalhador lia e assinava o Termo de Consentimento Livre e Esclarecido, que deixava clara a garantia de sigilo sobre a identidade do participante. A pesquisa foi registrada na Plataforma Brasil do Ministério da Saúde sob protocolo CAAE: 48770715.9.0000.0037 e aprovada pelo Comitê de Ética em Pesquisa da Pontifícia Universidade Católica de Goiás com o parecer n 1292041.

\section{Resultados}

Foram entrevistados todos os funcionários previstos inicialmente na pesquisa, num total de 18 , dos quais 15 do sexo feminino $(83,3 \%)$ e três do sexo masculino $(16,7 \%)$. Das funcionárias, cinco eram solteiras (33,3\%), uma casada (6,7\%), uma não informou o estado civil $(6,7 \%)$ e oito $(53,3 \%)$ divorciadas. Dos funcionários, um era casado $(33,3 \%)$ e dois eram divorciados $(66,7 \%)$. Daí resultando que $27,8 \%$ de todos os funcionários pesquisados são solteiros, $55,6 \%$ são divorciados e 5,6\% não informou seu estado civil.

Com relação ao local de trabalho, seis funcionárias $(40,0 \%)$ trabalhavam no CAPS, sete funcionárias $(46,7 \%)$ nas residências, duas (13,3\%) não informaram o local de trabalho. Dos funcionários do sexo masculino, todos trabalhavam nas residências. Tem-se então $33,3 \%$ de todos os funcionários prestando serviço no CAPS, 55,6\% servindo nas residências e $11,1 \%$ não informaram onde prestavam seu serviço.

Quanto à escolaridade observou-se que quatro mulheres $(26,7 \%)$ possuíam até o ensino fundamental e não existem homens com este nível de escolaridade, com o ensino médio foram entrevistadas seis mulheres $(40,0 \%)$ e três homens $(100,0 \%)$ com o ensino superior. Obteve-se no geral $22,2 \%$ de servidores com nível de escolaridade fundamental, 50,0\% com nível médio e 22,2\% com nível superior e 5,6\% não informou.

Com as respostas às perguntas do questionário SATIS-BR aos funcionários observou-se que em relação às questões 4 (Você se sente satisfeito no seu relacionamento com os outros colegas?) e 15 (Até que ponto você se sente satisfeito com o seu salário?), dois funcionários se consideram muito insatisfeitos, isso corresponde a $11,1 \%$. Percebe-se que o relacionamento com os colegas e o salário não são fatores que influenciam na qualidade da prestação do serviço por parte dos funcionários, uma vez que em relação à questão 4 , a soma dos indiferentes aos satisfeitos e muito satisfeitos $(n=1$ $+6+9$ ) é a maioria dos servidores, por outro lado com relação a questão 15, 50,0\% ( $n=2+7)$ dos funcionários se acharam muito insatisfeitos ou insatisfeitos ea outra metade $(n=1+8)$ indiferente ou satisfeito, no entanto, não temos nenhum servidor muito satisfeito.

Quanto à questão 16 (Você está satisfeito com os benefícios que recebe deste trabalho?), foi possível observar um percentual relativamente alto de funcionários $(43,6 \%)$ que marcaram como opções de resposta, "muito insatisfeito" ou "insatisfeito". Sobre estes dados, percebe-se a necessidade de os gestores considerarem uma política de aprimoramento dos benefícios, muitos deles de direito, como a concessão de insalubridade, vale transporte, auxílio alimentação, uniformes, férias remuneradas para os servidores de contrato especial ou outro dispositivo compensatório que nivelasse todos os funcionários com os mesmos benefícios. 
Com relação à questão 10 (Você se sente satisfeito com sua participação no processo de avaliação das atividades e/ou programas do serviço?), chama à atenção a elevada percentagem $(61,1 \%)$ de servidores "indiferentes" em um processo de grande importância para a efetiva condução e realização das atividades práticas do serviço.

Também "Indiferentes", respondem 33,3\%, com relação à pergunta 12 (Você percebe um bom clima no ambiente de trabalho?), isso corrobora com os comentários da pergunta 10. Já para a pergunta 19 (Até que ponto você acha que os profissionais do serviço de Saúde Mental compreendem o tipo de ajuda de que os pacientes necessitam?), essa indiferença é preocupante, uma vez que, para a plena execução das práticas terapêuticas, é necessário que todos os funcionários estejam imbuídos da mesma preocupação de conhecer, compreendere transmitir o sentimento de apoio e segurança para os pacientes.

De um modo geral, ao compilar e interpretar as perguntas feitas aos funcionários do CAPS e residências terapêuticas percebe-se que, embora não seja uma unanimidade, a grande maioria deles $(77,6 \%)$ está satisfeita ou muito satisfeita com o serviço que é prestado por esses dois serviços em saúde mental da cidade de Palmelo/GO.

Agora em relação aos usuários, foram entrevistadas nove pessoas, todas demonstraram boa capacidade de compreensão e entendimento durante as entrevistas. Destes residentes de residência terapêutica, cinco $(55,6 \%)$ eram do sexo feminino e quatro $(44,4 \%)$ masculino. Sendo que entre as mulheres, duas eram solteiras $(40,0 \%)$ e três $(60,0 \%)$ divorciadas. Já os homens, três $(75,0 \%)$ eram solteiros e um divorciado $(25,0 \%)$.

O morador mais novo possuía 44 anos e o mais velho 70 anos, três estavam na faixa dos 60 anos e quatro na faixa dos 50 anos. Dos nove moradores, cinco eram semialfabetizados e os outros quatro analfabetos e, indagados porque não estudaram, responderam que moravam na zona rural e no passado os pais não davam importância para os estudos, pois priorizavam o auxílio no trabalho em casa.

$\mathrm{Na}$ entrevista os residentes foram questionados sobre a maneira como foram tratados, em termos de respeito e dignidade, conclui-se que $44,4 \%$ dos moradores sempre se sentiram respeitados, enquanto que $33,3 \%$ sentiram-se mais ou menos respeitados. Reconhecer e aceitar a deficiência do morador faz toda a diferença.

Compiladas as questões 2,3 e 4, que interrogavam, respectivamente, se o morador sentiu que foi ouvido pelo profissional que o admitiu, se tal profissional pareceu compreender $o$ problema do paciente e se a equipe compreendeu o tipo de ajuda que o futuro morador necessitaria, observou-se respostas positivas em relação à equipe atuante nas residências.
Segundo os entrevistados, $55,6 \%$ acharam que a pessoa que o admitiu lhe ouviu bastante, $66,7 \%$ sentiram que o profissional compreendeu muito bem o seu problema e $44,4 \%$ disseram que a equipe de trabalhadores compreendeu muito bem 0 tipo de ajuda que o morador necessitaria naquele momento.

Quando questionados sobre o tipo de ajuda dada pelo serviço das residências, sobre a orientação em relação ao tratamento e se a equipe técnica estava ajudando (questões 5,6 e 7), verificou-se que $66,6 \%$ dos moradores sentiam que obtinham muita ajuda, aproximadamente $90,0 \%$ estavam satisfeitos ou muito satisfeitos com a orientação que lhes foi feita sobre o tratamento.

Os entrevistados também afirmaram que os profissionais eram muito amigáveis (55,6\%), 66,7\% disseram que a equipe é muito competente e que a pessoa com quem ele mais foi cuidado é competente. Isso demonstra o grau de satisfação, que os usuários possuem pela equipe.

Observa-se um contraponto nas respostas das questões de 1 a 12, em que sempre demonstraram boa aceitação da equipe e do ambiente, todavia quando questionados se o serviço de residência terapêutica poderia ser melhorado $44,4 \%$ responderam que "sim" e 55,6\% não souberam responder. Talvez seja um reflexo da limitação mental destes residentes, em melhor expressar suas opiniões.

No que se refere aos dados qualitativos, observou-se nos discursos dos entrevistados que a equipe atuante em residências terapêuticas foi questionada sobre o que mais gosta no serviço, um profissional respondeu da seguinte forma: O que eu mais gosto é de ser uma profissional comprometida com os usuários, gosto da saúde mental como um todo, da humanização dos pacientes e de como os mesmos me fazem bem e me motivam a ser cada dia melhor.

Quando os funcionários foram interrogados sobre os aspectos de que não gostam no serviço, demonstraram diversas insatisfações, dentre elas o descompromisso: A má valorização dos gestores públicos em relação aos próprios pacientes, principalmente das residências terapêuticas e a desvalorização da equipe. Percebemos que até os dias atuais a valorização dos portadores de transtornos mentais ocorre de forma lenta e até mesmo esquecida. É importante salientar que os profissionais vivem em constante estresse pelo trabalho na saúde mental: a gente trabalha sobre um estresse físico e mental totalmente são comuns.

Analisando os discursos dos usuários, observou-se a simplicidade destes, aparentavam ser gratos e felizes por ter um lar, quando lhes foi perguntado o que mais gostavam na casa, respondeu, a maioria, o quarto ou tudo. Ou, ainda, do que menos gostava na casa, a maioria respondeu que não há 
nada que não gostem. Alguns ainda recordavam da vida em manicômios e outros dos lugares por onde perambulavam em busca de abrigo e comida.

Os moradores das residências terapêuticas de Palmelo/GO demonstraram plena satisfação pelo auxílio diário que recebiam, cada um com sua particularidade, uns eram sociáveis e gostavam de caminhar e conversar com a vizinhança, outros preferiam reservar-se e viver somente nos cômodos da casa. Falaram também do incômodo que é a área externa, que para eles é muito quente e outros disseram que não havia nada na casa que deveria melhorar, pois para eles estava tudo perfeito.

\section{Discussão}

Os resultados demonstraram claramente a importância atribuída pelos profissionais ao serviço de residência terapêutica. Corrobora com esse dado, um estudo realizado no estado do Espírito Santo, que alguns trabalhadores de saúde mental apesar de não serem preparados para o exercício laboral, eram responsáveis imediatos pelos moradores de residência terapêutica e tinham considerável importância em seu processo de reinserção social e exercício de sua cidadania ${ }^{14}$.

Embora satisfeitos com seu trabalho nas residências terapêuticas, é importante salientar que a satisfação no trabalho, que já vem sendo amplamente estudada, se reflete no produto final gerado pelo profissional, podendo afetar na saúde física e mental, atitudes, comportamento profissional, social, tanto com repercussões para a vida pessoal e familiar do indivíduo como para o local de trabalho. Assim, é preciso incentivar cada vez mais o trabalhador em saúde mental por meio de motivação pessoal, remuneração adequada, promoção, reconhecimento e condições adequadas de ambiente de trabalho ${ }^{15}$.

O ambiente organizacional com bons níveis de satisfação pode gerar o sucesso do tratamento, no qual está diretamente relacionado ao modo de como o paciente compreende sua doença ${ }^{16}$. É sabido que a doença mental, explicada por causas biológicas, psicológicas e sociais, necessita de assistência adequada de profissionais, com a finalidade de ressocialização do doente e de apoio adequado para estes. Nesse sentido, o cotidiano nas residências terapêuticas deve ser sadio e oferecer ao morador autonomia, produção da subjetividade e, principalmente, assegurar o direito de assistência e tratamento especializado ${ }^{7}$.

A maioria dos profissionais demonstrou gostar de estar com os moradores. O marco inicial de abrigar pessoas com doença mental veio por meio da II Conferência Nacional de Saúde Mental, em dezembro de 1992, que ressaltou a importância estratégica da implementação de "lares abrigados" para a reestruturação da assistência em saúde mental no País? .
Por isso, os profissionais das residências de Palmelo/GO se mostraram conscientes de que os moradores não possuem suporte familiar, gostam da reciprocidade que os residentes transmitem no cotidiano, aprendem com eles, o que possibilita a vivência em sociedade, autonomia física e psíquica dos residentes.

Considerando o que se propõe às residências terapêuticas, é possível observar que em Palmelo, aparentemente, as moradias cumprem essa finalidade tem se desenvolvido e buscado atender as propostas provenientes da reforma psiquiátrica. Tanto que os profissionais atuantes daquelas casas exerciam uma prática contrária ao que foi, na psiquiatria tradicional, que se caracterizava pelo isolamento, tratamento punitivo, e contenção física e química de pacientes com transtornos mentais ${ }^{6}$.

A residência terapêutica surgiu após um passado nefasto, com ela veio o anseio de se eliminar a realidade, a cultura institucional e suas consequências, como violência, falta de dignidade, isolamento e injustiça ${ }^{17}$. Todavia, já há quase duas décadas da reforma psiquiátrica no Brasil, ainda há certa fragilidade no sistema, os recursos e profissionais qualificados são escassos, consequentemente, o público-alvo vive marginalizado aguardando por abrigo e uma vida digna.

Com a implantação do novo modelo de assistência à saúde mental, isto representou um desafio para os profissionais, uma vez que tiveram que adotar novos saberes, tecnologias e metodologias de trabalho para atender as necessidades de portadores de transtornos mentais ${ }^{6}$. Em se tratando da pequena cidade de Palmelo/GO, que era tida como referência no país em tratamento de transtornos mentais, ainda é um grande desafio, pois diversos indivíduos foram abandonados por seus entes queridos naquele município.

O lar é muito benéfico aos usuários, por oferecer a eles a inserção em um ambiente próximo ao que se pode considerar como uma residência, tal que, progressivamente, se tornem capacitados para o exercício de direitos e deveres da vida comum ${ }^{6}$. Todavia, pela delicadeza das questões com as quais os profissionais lidam, é importante que obtenham, frequentemente, informações essenciais sobre os moradores do serviço residencial e sobre as questões que envolvem a transformação da atenção à saúde mental, para que tais ensejos reflitam na melhoria do desenvolvimento psicossocial do residente ${ }^{14}$.

Assim, observa-se que essas circunstâncias do ambiente de trabalho e de vida são prerrogativas que levam o trabalhador a exercer cuidados sobre si mesmo constantemente. Bem como, é um incentivo para o poder público, em reconhecer o valor de tal profissional, de forma a garantir-lhes condições ideais de trabalho, como capacitação e remuneração de todos os direitos ${ }^{18,19}$. Tudo isso contribuirá sobremaneira para o cuidado 
digno e integral prestado ao usuário da residência terapêutica, objetivo primordial deste tipo de serviço em saúde mental.

\section{Conclusão}

O presente estudo abordou a satisfação de profissionais e usuários do serviço de residência terapêutica sediado no município de Palmelo/GO. Essas experiências são de extrema importância para dar bases para a rede de serviços em saúde mental de acompanhamento a portadores de transtornos mentais e para a melhoria destes programas.

Foi constatado nos dados quantitativos que apenas 1,9\% dos profissionais estavam insatisfeitos com o serviço, a maioria, $62,7 \%$, estava satisfeita com o trabalho que realizavam. Com relação aos residentes, alguns dados chamam a atenção, como $44,4 \%$ se sentiam respeitados pelos profissionais, $66,7 \%$ sentiam que os profissionais compreendiam muito bem seus problemas.

Já os dados qualitativos, foi possível vislumbrar como o residente avaliou o serviço. Foram notórios o orgulho e a satisfação que o morador demonstrou ao relatar sobre a convivência na residência terapêutica, qualificando a moradia como perfeita e magnífica (expressão de um morador). Quando observados os discursos dos profissionais, verificou-se que havia certo descontentamento destes em relação à esfera pública, que pouco oferece incentivos à capacitação, ao reconhecimento.

Como propostas para melhor satisfação dos profissionais, principalmente no que se refere às condições da legislação trabalhista é necessário se abrir uma via para o diálogo permanente, onde a diplomacia abra uma possibilidade de abertura com o poder público. Outra maneira também de se buscar melhorias, seria inserir propostas viáveis ao Conselho Municipal de Saúde que pudessem ser levadas e cobradas do executivo.

Por outro lado, com relação aos usuários, apesar do alto grau de satisfação dos mesmos, é importante que se mantenha a constante vigilância por parte dos órgãos fiscalizadores das residências terapêuticas e dos CAPS, para que a prestação do serviço se mantenha sempre satisfatória e de bom nível.

\section{Agradecimentos}

O Presente trabalho foi financiado pela Fundação de Amparo à Pesquisa do Estado de Goiás - FAPEG.

\section{Referências Bibliográficas}

1.Schrank G, Olschowsky A. O centro de atenção psicossocial e as estratégias para inserção da família. Rev. esc. enferm. USP. 2008;42(1):127-34.

2. Wetzel C, Kantorski LP, Souza J. Centro de Atenção Psicos- social: trajetória, organização e funcionamento. Revista Enfermagem UERJ. 2008;16(1):39-45.

3. Gonçalves AM, Sena RR. A reforma psiquiátrica no Brasil: contextualização e reflexos sobre o cuidado com o doente mental na família. Rev Latino-Am Enferm. 2001;9(2):48-55.

4. Onocko-Campos RT, Furtado JP. Entre a saúde coletiva e a saúde mental: um instrumental metodológico para avaliação da rede de Centros de Atenção Psicossocial (CAPS) do Sistema Único de Saúde. Cad. Saúde Pública. 2006;22(5):1053-62.

5. Brasil. Reforma psiquiátrica e política de saúde mental no Brasil. OPAS. Brasília: Ministério da Saúde; 2005.

6. Martins GCS, Moraes AEC, Santos TCF, Peres MAA, Almeida Filho AJ. O processo de implantação de residências terapêuticas em Volta Redonda - Rio de Janeiro. Texto contexto - enferm. 2012;21(1):86-94.

7. Brasil. Residências Terapêuticas: o que são, para que servem. Brasília: Ministério da Saúde; 2004.

8. Furtado JP, Nakamura E, Generoso CM, Guerra AMC, Campos FB, Tugny A. Inserção social e habitação: um caminho para a avaliação da situação de moradia de portadores de transtorno mental grave no Brasil. Interface (Botucatu). 2010;14(33):389-400. 9. Aguiar BL. Serviços de Residências Terapêuticas: entre a tutela e a autonomia, a incansável busca pelo cuidado. Dissertação de Mestrado. Programa de Pós-Graduação em Psicologia. Universidade Federal de Pernambuco. 2009.

10. Bandeira M, Pitta AMF, Mercier C. Escalas brasileira de avaliação da satisfação (SATIS-BR) e da sobrecarga (IMPACTO-BR) da equipe técnica em serviços de saúde mental. J. bras. psiquiat. 2000;49(4):105-15.

11. Lefèvre F, Lefèvre AMC, Teixeira JJV. O discurso do sujeito coletivo: uma nova abordagem metodológica em pesquisa qualitativa. Caxias do Sul: EDUCS; 2000.

12. Flick U. Qualidade na pesquisa qualitativa: coleção pesquisa qualitativa. São Paulo: Bookman; 2008.

13. Figueiredo MZA, Chiari BM, Goulart BNG. Discurso do sujeito coletivo: uma breve introdução à ferramenta de pesquisa qualiquantitativa. Distúrbios da Comunicação. 2013;25(10):129:36.

14. Ribeiro Neto PM, Avellar LZ. Conhecendo os cuidadores de um serviço residencial terapêutico. Mental. 2009;7(13).

15. Martinez MC, Paraguay AIBB. Satisfação e saúde no trabalho: aspectos conceituais e metodológicos. Cadernos de psicologia social do trabalho. 2003;6:59-78.

16. Spadini LS, Souza MCBM. A doença mental sob o olhar de pacientes e familiares. Rev. esc. enferm. USP. 2006;40(1):123-7. 17. Borsa JC, Eidelwein K. Conhecendo a realidade da saúde mental no Rio Grande do Sul. 2005. Disponível em: http:// repositorio.furg.br/. Acesso em: 20/01/2016 as 17:30. 
18. Bernardes AG, Guareschi NMF. Trabalhadores da saúde mental: cuidados de si e formas de subjetivação. Psicologia USP. 2004;15(3):81-101.

19. Brasil. Saúde Mental em Dados. Brasília: Ministério da Saúde; 2012. 